
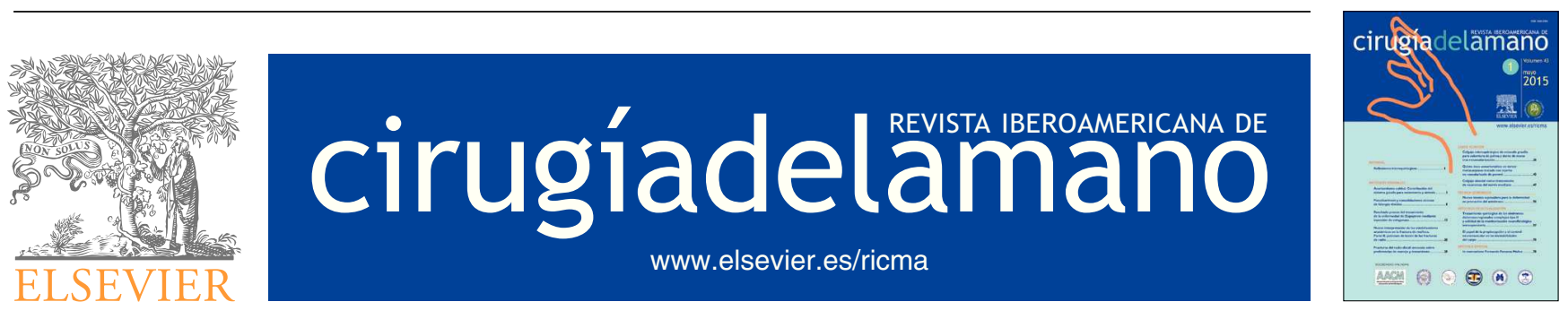

\title{
Reflexiones microquirúrgicas
}

\section{Microsurgical reflections}

Sin lugar a dudas, el gran avance de las últimas décadas en cirugía de la mano ha sido la incorporación de las "técnicas microquirúrgicas", haciendo posible reparaciones de graves lesiones de pequeñas estructuras anatómicas (arterias, venas, nervios...), consiguiendo resultados realmente inimaginables por su calidad y perfección.

Desde hace más de treinta y cinco años, mi actividad profesional ha estado polarizada hacia la cirugía de mano, en su vertiente del accidente laboral fundamentalmente, al igual que a la cirugía secundaria reconstructiva. En mis primeros años de dedicación a la mano, al conocer las técnicas microquirúrgicas, sentí un entusiasmo desmedido hacia la reparación de cualquier estructura anatómica lesionada, asistiendo a congresos, simposios y cursos de carácter nacional o internacional allá donde los hubiese.

En los primeros años de mi vida profesional, me convertí en un "reimplantador", forzando permanentemente las indicaciones, y posteriormente decidí hacer mi tesis doctoral con el título "Estudio socio-clínico-económico de los reimplantes en Aragón"; bien es verdad que más del 70\% de los casos intervenidos correspondían a pacientes trasladados de otras comunidades autónomas, ya que en esa época solo existían tres o cuatro centros en España que asumieran este tipo de lesiones.

Los resultados de aquel estudio fueron para mí sorprendentes en algunos aspectos:

1) Socialmente la microcirugía fue impactante, con gran repercusión a nivel del ciudadano de a pie y de los medios de comunicación. Algunos medios lo calificaban como milagroso, pues veían cómo una persona que había sufrido una amputación de su extremidad la volvía a tener reimplantada al cabo de unas horas y recuperaba sus movimientos y sensibilidad.

2) Desde el punto de vista médico, fue un gran logro poder suturar con medios ópticos de amplificación arterias, venas y nervios de calibres inferiores a $1 \mathrm{~mm}$, con agujas de 50 y 70 micras e hilos de $10 / 0$ y $11 / 0$, consiguiendo reparaciones impensables en esa época. Los resultados de la cirugía eran espectaculares desde el punto de vista funcional y estético, permitiendo a los pacientes en su gran mayoría volver a las actividades de su vida ordinaria.

3) En el aspecto económico había dos problemas a resolver:

- Por un lado, la necesidad de montar un pequeño quirófano experimental para que se pudieran entrenar los cirujanos y equiparlo con medios ópticos de amplificación (microscopio y gafa lupa). Para ello, hubo que conseguir convencer a los administradores de los hospitales de que en breve ello supondría beneficios sociales por la gratitud de los pacientes y los empresarios.

- Por otro lado, fueron sorprendentes los resultados económicos. En las mutuas de accidentes de trabajo los gerentes y administradores se rigen por la cuestión económica. Una amputación de una mano de un trabajador manual es una incapacidad permanente total, que la mutua correspondiente tiene que indemnizar económicamente con una cantidad determinada. En función de la parte lesionada de la mano hay diferentes tipos de incapacidades: baremo, incapacidad permanente parcial (IPP), incapacidad permanente total (IPT), incapacidad permanente absoluta (IPA) y gran invalidez. Por lo cual las mutuas tienen elevados costes.

La aplicación de las técnicas microquirúrgicas supuso un cambio rotundo, evitando pagar indemnizaciones por un valor de casi mil millones de las antiguas pesetas (año 1996) en los cien casos controlados. El ahorro fue en las amputaciones de manos y pulgares; sin embargo, no fue rentable en las amputaciones de los dedos largos.

En general la valoración global de los pacientes fue buena, salvo una minoría que no estaban satisfechos con los resultados obtenidos e incluso llegaban a esconder su mano, usándola únicamente cuando estaban solos o ante el cirujano en sus revisiones; es lo que vinimos a denominar "manos 
bolsillo". Esto me impactó y me cambió mis indicaciones quirúrgicas, ya que casos muy complejos y en los que habíamos hecho alardes técnicos de gran dificultad de los que nos sentíamos orgullos y calificábamos de excelentes para el paciente no eran satisfactorios, puntuándolos negativamente en la encuesta.

La experiencia nos demostró que algo no estaba bien planteado y nuestra pregunta era CUÁNDO DECIR NO EN LAS INDICACIONES QUIRÚRGICAS. Decidimos que lo primero había que pensar en el paciente, ser humilde como cirujano y dejar "nuestro Yo" de hechicero que todo lo cura a base de innumerables cirugías, para conseguir un objetivo personal y alardear de los casos en congresos y simposios médicos.

Desde 1996 mi actitud con respecto a las indicaciones cambió sustancialmente. En muchos casos de amputación de dedos largos, si no se prevé un buen resultado articular que permita flexo-extensión completa, es preferible una amputación estética, dejando una mano con cuatro dedos que estética y funcionalmente es bien aceptada que no una mano con un dedo rígido que molestará y con el riesgo de sufrir nuevos accidentes.

En cirugía reconstructiva de la mano, hay que informarse muy bien de las necesidades del paciente; para ello es importante dejar hablar al paciente en la primera visita, para que pueda explicar las dificultades que tiene en su día a día y preguntar qué querría mejorar en el futuro, no olvidando que nuestra obligación como médico es la de dar gusto al paciente en sus deseos de mejorar tanto funcional como estéticamente. Actualmente nosotros hacemos "CIRUGÍA A LA CARTA", ofreciendo un menú de las distintas opciones que hay en la reconstrucción de la mano. En la cirugía reconstructiva del pulgar, explicamos al paciente las distintas técnicas existentes (dedo del pie a la mano, elongaciones de falanges o metas, trasposiciones...) y con ayuda de un ordenador le enseñamos fotografías y videos de casos resueltos con estas técnicas, para que pueda ver sus resultados, y en algunos casos se le proporciona el teléfono de pacientes que han sido operados por nosotros, para que intercambien opiniones entre ellos que les permitan tomar una mejor decisión. Nunca se debe tomar la decisión en una primera visita, pues se debe dejar tiempo suficiente para que el paciente piense con tranquilidad qué puede ser lo mejor para su mano, ya que son personas que han sufrido mucho e incluso les repele verse la mano mutilada. En la segunda visita les puedes aconsejar, pero la decisión final la debe tomar siempre el paciente y no el médico. Si el cirujano complace al paciente en su decisión, habrá una mejor predisposición en la relación médico-paciente.

El futuro de la microcirugía seguirá siendo extraordinario y sumamente necesario para la reparación de las graves lesiones de mano y nervios periféricos. Pero sufrirá grandes cambios; en la actualidad desvestimos un santo para vestir otro, trasladando estructuras anatómicas de un lugar a otro, produciendo gran morbilidad en las zonas donantes. No está lejos el día en que podamos disponer de tejidos y órganos creados a partir de células madre y con un poco de ciencia ficción, si dichas células madre provienen del pelo del cuero cabelludo, se podría conseguir la misma velocidad de crecimiento evitando los tratamientos de inmunosupresión cuando los tejidos son heterólogos.

En el momento presente se trabaja como los antiguos chapistas reparando las piezas, pero estos en la actualidad piden a fábrica las piezas de los distintos modelos, es decir, utilizan piezas idénticas del modelo a reparar, lo que disminuye el tiempo de reparación y los costes. Imaginemos por un momento que, a la hora de reparar una mano con cirugía secundaria, pudiéramos pedir al futuro "departamento de ingeniería genética" tejidos u órganos autólogos para su implante.

Ahora todo esto parece un sueño inalcanzable, pero hay que pensar que hace 40 años reimplantar un dedo era como un milagro, siendo que a día de hoy se hace en muchos hospitales de todo el mundo.

Volviendo a la realidad, quiero decir con gran rotundidad que la microcirugía es absolutamente indispensable para cualquier cirujano de mano y que su formación debe hacerse en cursos de microcirugía en rata, para obtener la destreza necesaria y, una vez superado este nivel técnico, los cirujanos deben acudir a las salas de anatomía, para aplicar lo aprendido en manos de cadáver y poder diseñar también nuevas intervenciones. No hay que olvidar jamás que las CURVAS DE APRENDIZAJE siempre deben hacerse en quirófanos experimentales y salas de anatomía y NUNCA en manos de pacientes. 